\title{
EXPERIÊNCIAS DE DOENTES CRÍTICOS COM A VENTILAÇÃO MECÂNICA INVASIVA
}

\author{
Experiences of critically ill patients with invasive mechanical ventilation \\ Las experiencias de pacientes críticos con ventilación mecánica invasiva
}

Cristian Dornelles ${ }^{1}$

Gabriele Brito de Oliveira²

Camila Rose G.B. Schwonke ${ }^{3}$

José Richard de Sosa Silva ${ }^{4}$

\section{RESUMO}

0 objetivo deste estudo foi conhecer as experiências vividas por pacientes que fizeram uso de ventilação mecânica invasiva em Unidades de Terapia Intensiva de dois hospitais do extremo sul do Brasil. A presente pesquisa foi conduzida na perspectiva qualitativa, sendo realizada com 10 pacientes que salientaram suas principais dificuldades e necessidades durante o período em que fizeram uso de ventilação mecânica invasiva. Os resultados apontam que as dificuldades relatadas relacionaram-se especialmente com a presença da via aérea artificial, sendo elas: sensação de sufocamento, náuseas, lesões decorrentes do tubo endotraqueal, acúmulo de secreções no tubo endotraqueal e cavidade oral e afonia. Além disso, os pacientes referiram necessidades de comunicação, sede e alterações da rotina pessoal. Os achados deste estudo elucidaram a vivência do paciente crítico, mediante esse recurso invasivo, trazendo elementos importantes a serem considerados para o cuidado de enfermagem.

Palavras-chave: Respiração artificial. Terapia intensiva. Enfermagem.

\begin{abstract}
The aim of this study was to identify the experiences of patients who used invasive mechanical ventilation in intensive care units of two hospitals in Southern Brazil. This research was conducted in a qualitative way, consisting of 10 interviewees, who emphasized their main difficulties and necessities during the period in which they used invasive mechanical ventilation. The results indicate that the difficulties reported were specially related to the presence of the artificial airway, such as: suffocation felling, nausea, injuries caused by the endotracheal tube, accumulation of secretions in the endotracheal tube and oral cavity and aphonia. In addition, the patients reported other problems such as: communication needs, thirst, and changes in their personal routine. Our findings elucidated the experience of critically ill patients through this invasive feature, bringing important issues to be considered for nursing care.
\end{abstract}

Keywords: Artificial Respiration. Intensive Care. Nursing.

\section{Resumen}

El objetivo de este estudio fue conocer las experiencias de los pacientes que hicieron uso de la ventilación mecánica invasiva en Unidades de Cuidados Intensivos de dos hospitales en el extremo sur de Brasil. La presente investigación fue conducida en la perspectiva cualitativa, siendo compuesta por 10 entrevistados, que destacaron sus principales dificultades y necesidades durante el periodo en que hicieron uso de ventilación mecánica invasiva. Los resultados apuntan que las dificultades relatadas se relacionaron especialmente a la presencia de la vía aérea artificial, siendo ellas: sensación de sofocarse, náuseas, lesiones decurrentes del tubo endotraqueal, acumulo de secreciones en el tubo endotraqueal, cavidad oral y afonía. También los pacientes refirieron necesidades comunicacionales, sede y alteraciones de la rutina personal. Los hallazgos de este estudio elucidaron la vivencia del paciente crítico mediante este recurso invasivo, trayendo puntos importantes a considerarse para el cuidado de enfermería.

Palabras clave: Respiración Artificial. Cuidados Intensivos. Enfermería.

\footnotetext{
'Enfermeiro da Comissão de Controle de Infecção Hospitalar do Hospital Sociedade Portuguesa de Beneficência de Pelotas/RS. Graduado pela Faculdade Anhanguera Educacional de Pelotas-RS. Brasil. Pelotas-RS. Brasil. E-mail: dornelles.cristian@gmail.com; '2Enfermeira. Graduada pela Faculdade Anhanguera Educacional de Pelotas/RS. Brasil. Pelotas-RS. Brasil. E-mail: gabii_brito@hotmail.com; ${ }^{3}$ Mestre em Enfermagem e Doutoranda do Programa de Pós Graduação em Enfermagem FURG. Enfermeira da Unidade de Terapia intensiva Adulto do Hospital Escola da UFPEL. Pelotas-RS. Brasil. E-mail: kmila.enf@rig.com.br ; ${ }^{4}$ Enfermeiro, Mestre em Enfermagem e Doutorando do Programa de Pós-Graduação em Enfermagem FURG, Coordenador da Faculdade de Enfermagem Anhanguera de Pelotas/RS. Pelotas-RS. Brasil E-mail: jrichard.sosa@gmail.com
} 


\section{INTRODUÇÃO}

Na enfermagem, um grande marco na seleção de pacientes graves foi Florence Nightingale, que, na Guerra da Crimeia, em 1854, classificou os doentes de acordo com o grau de dependência, dispondo-os nas enfermarias de tal maneira que os mais graves ficassem próximos à área de trabalho dos enfermeiros, para maior vigilância e melhor atendimento".

No Brasil, as Unidades de Terapia Intensiva (UTIs) tiveram início na década de 1970, possibilitando a missão de prestar cuidados de excelência, visando à recuperação do paciente grave, pela monitorização constante, utilizando recursos operacionais adequados, gerando e divulgando conhecimentos por meio de pesquisa científica e mantendo sempre uma visão holística².

A assistência de enfermagem na UTI é um aspecto fundamental para o processo de tratamento e reabilitação do paciente. 0 enfermeiro na Unidade de Terapia Intensiva deparase com um ambiente de elevado nível tecnológico e de complexidade, sendo necessário que esse profissional se respalde no conhecimento científico, para assim conduzir o atendimento ao paciente com a devida segurança $\mathrm{a}^{2-3}$.

$\mathrm{Na}$ atualidade, o cuidado em terapia intensiva, mais do que no passado, tem sido balizado pela incorporação de novas tecnologias, o que amplia perspectivas para a melhora da qualidade do trabalho/assistência e da vida dos sujeitos que cuidam e daqueles que são cuidados ${ }^{4}$. Muitos dos pacientes internados na UTI apresentam alterações importantes na função respiratória, sendo incapazes de manter uma ventilação espontânea eficaz, necessitando, portanto, de aparelhos artificiais que assumam esse papel. Desse modo, a ventilação mecânica é qualquer método de respiração que utiliza um aparelho mecânico para aumentar ou satisfazer completamente as necessidades respiratórias do doente, promovendo a expansão pulmonar pelo fornecimento de pressão positiva ou negativa ao sistema respiratório ${ }^{5}$, possibilitando assim, a diminuição do trabalho respiratório, pelo aumento da oxigenação e diminuição do acúmulo de dióxido de carbono nos pulmões e na circulação sanguínea².

A enfermagem, na assistência ventilatória, tem como objetivos manter a oxigenação e perfusão adequadas dos órgãos e tecidos para prevenir a hipóxia. Para tanto, cabe à enfermagem monitorar sinais e sintomas de hipóxia, tais como alterações de comportamento, letargia, cefaleia, agitação, perda de concentração, taquicardia, taquipneia, aumento súbito da pressão arterial, arritmias, cianose e sinais de alteração do padrão respiratório, comunicar à equipe médica as alterações observadas e administrar a terapia prescrita. Também cabe à enfermagem prevenir as complicações associadas à ventilação mecânica, garantir a sincronização da respiração do paciente com o ventilador e manter o bom funcionamento do ventilador mecânico ${ }^{6}$.
No entanto, os pacientes submetidos à ventilação mecânica estão expostos a medidas bastante agressivas, e por eles desconhecidas, o que pode causar ansiedade quanto à conduta e aos procedimentos realizados. Assim, é necessário que os profissionais de enfermagem compreendam as dificuldades e necessidades experienciadas pelos doentes críticos durante o uso dessa terapêutica, de forma a subsidiarem um cuidado voltado para as reais expectativas dos indivíduos, considerando sua singularidade e buscando estabelecer meios de comunicação efetivos que promovam a participação do paciente nos cuidados e na terapêutica².

Assim, o presente estudo tem como objetivo: Conhecer as experiências vividas por doentes críticos que fizeram uso de ventilação mecânica invasiva em Unidades de Terapia Intensiva Adulto de dois hospitais do extremo sul do Brasil.

\section{MÉTODO}

0 presente estudo configura-se como pesquisa qualitativa realizada em duas Unidades de Terapia Intensiva Adulta de dois hospitais gerais de uma cidade do extremo sul do Brasil. Foram selecionados 10 informantes para o estudo, os quais, antecipadamente, receberam informações quanto aos aspectos éticos da pesquisa e assinaram o Termo de Consentimento Livre e Esclarecido, conforme determina a Resolução 196/96 da Comissão Nacional de Ética em Pesquisa que dispõe sobre Pesquisas Envolvendo Seres Humanos. Os critérios para a seleção dos sujeitos da pesquisa foram: ser adultos, acima de dezenove anos, que tivessem utilizado ventilação mecânica invasiva por um período mínimo de 48 horas, que concordassem em participar do estudo, que não estivessem traqueostomizados no momento da coleta de dados e que permitissem que os dados obtidos fossem divulgados. Os entrevistados da pesquisa foram identificados pela letra "P", seguida por uma ordem numérica.

Os dados foram coletados nos meses de agosto e setembro de 2011, por meio de um roteiro semiestruturado de entrevista. Esse roteiro apresentava sete questões que buscaram caracterizar os informantes do estudo (idade, estado civil, profissão escolaridade, tempo de permanência na UTI, tempo de ventilação mecânica, doença que motivou o uso da ventilação mecânica) e cinco questões aber tas que permitiram o relato dos informantes sobre o uso da ventilação mecânica, dificuldades experienciadas, percepção quanto à qualidade dos cuidados dispensados a eles, pelos profissionais de saúde, durante o uso da ventilação mecânica. Os dados foram coletados após a alta dos doentes críticos das unidades de terapia intensiva, após serem transferidos para unidades de internação clínica ou cirúrgica.

Para a delimitação do número de sujeitos entrevistados, foi utilizado o critério de saturação de dados, que visa a determinação do momento em que a busca de novos sujeitos não acrescente mais nenhum dado novo para a investigação $0^{7}$. Todas as entrevistas foram gravadas e, 
posteriormente, transcritas de maneira digitalizada. 0 projeto de pesquisa foi aprovado pelo Comitê de Ética da Santa Casa de Misericórdia de Pelotas/RS, protocolado com o número de identificação 154/2011.

Os dados obtidos foram analisados na perspectiva da análise textual, a qual envolve identificar e isolar enunciados dos materiais a ela submetidos, categorizando-os e produzindo textos, integrando neles textos descritivos e interpretativos, tendo como base de sua construção o sistema de categorias desenvolvido na análise ${ }^{8}$. Os resultados do estudo foram organizados em duas categorias: Dificuldades do doente crítico quanto ao uso da ventilação mecânica invasiva; Necessidades dos doentes críticos em ventilação mecânica invasiva.

\section{RESULTADOS E DISCUSSÃO}

\section{Características dos informantes do estudo}

Os informantes deste estudo eram em sua maioria do sexo masculino (6-60\%) com média de idade de 50 anos. 0 tempo de permanência na UTI foi em média 5,5 dias, submetidos a uma média de 71 horas de ventilação mecânica. Quanto às patologias que motivaram o uso do suporte ventilatório invasivo, três pacientes apresentaram insuficiência respiratória aguda por pneumonia bacteriana, seis eram pacientes oriundos de cirurgias cardíacas (4 revascularizações do miocárdio, 1 correção de seio aórtico e 1 correção de aneurisma de válvula mitral) e um era politraumatizado.

\section{Dificuldades do doente crítico quanto ao uso da ventilação mecânica invasiva}

Essa categoria apresenta as dificuldades vivenciadas pelos doentes críticos durante o uso do suporte ventilatório invasivo. As principais dificuldades relatadas pelos pacientes, nesse período, relacionavam-se à presença da via aérea artificial, que, segundo eles, provocava sensação de sufocação; náuseas; lesões decorrentes ao uso do tubo endotraqueal; acúmulo de secreção nesse tubo e na cavidade oral e, finalmente, afonia.

A sensação de sufocação estava presente nos relatos de todos os informantes da pesquisa, podendo estar relacionada com baixas dosagens de drogas sedativas, presença do tubo orotraqueal e também com a assincronia produzida pela presença de drive respiratório do doente em vigência de um modo ventilatório que não contempla ciclos espontâneos.

[...] Ela parece que estava me sufocando, eu queria respirar e a sensação que eu tinha era que eu queria respirar e não conseguia, por causa do tubo, dava uma sensação horrível, acho que eu me debatia porque aquela sensação que eu tinha é que eu queria respirar e algo estava me impedindo de respirar [...] (P1).

[...] Queria respirar e aquela sufocação me impedia, aquela sensação é horrível, a única sensação que eu senti foi essa sufocação, mais nada, essa agonia de querer respirar e não poder. Pensei que iria morrer de falta de ar, asfixiada [...] (P6).

É necessário, antes mesmo de se falar sobre os conceitos que envolvem os pacientes em ventilação mecânica, elucidar as implicações das vias ar tificiais na fisiologia respiratória. 0 tubo traqueal possui uma resistência maior do que a das vias aéreas superiores, aumentando a resistência da via aérea em aproximadamente $200 \%$. Cada milímetro de redução do diâmetro do tubo aumenta em cerca de $25 \%$ a $100 \%$ essa resistência, cujos principais determinantes são: diâmetro, comprimento, densidade e viscosidade do gás. Cabe aos profissionais envolvidos no cuidado a esses pacientes considerar que o diâmetro do tubo deve ser o maior possível para reduzir o turbilhonamento do fluxo aéreo.

As náuseas relatadas pelos doentes críticos, como uma dificuldade vivenciada durante o período que estiveram em ventilação mecânica, também se relacionam à presença de uma via aérea artificial. Essa constatação aponta para a necessidade de um olhar atento da equipe de saúde, durante o cuidado, pois essa sensação eleva o risco em potencial de aspiração pulmonar de conteúdo gástrico, podendo desencadear assim um quadro de pneumonia aspirativa e também de uma possível autoextubação.

[...] Queria vomitar e não conseguia, foi a pior situação que aconteceu [...] (P2).

[...] A única dificuldade maior que tive foi com a náusea, que persistia sempre quando estava lá [...] (P4).

A adequada sedação dos doentes críticos, durante 0 preparo para o procedimento de intubação endotraqueal e, também, durante o uso da ventilação mecânica, pode minimizar as respostas fisiopatológicas de tais situações. Especialmente durante o procedimento de intubação, a inibição da resposta ao estresse produzido pelo procedimento, por meio de drogas sedativas, reduz os níveis de catecolaminas e neuropeptídios circulantes, produzindo, assim, efeitos benéficos em doentes críticos $^{10}$.

As lesões na comissura labial foram relatadas como dificuldades sentidas pelos pacientes durante a ventilação mecânica e que decorre, na maioria das vezes, quando não há rodízio da fixação da prótese traqueal e/ou quando o tubo endotraqueal não é estabilizado por um profissional da saúde, durante a mudança de decúbito do paciente, facilitando, assim, o deslocamento e 0 atrito do tubo com a cavidade oral. Estas lesões também podem ocorrer durante o procedimento de entubação orotraqueal, sendo que a realização do rodízio dos locais de posicionamento da prótese traqueal tem que ser uma preocupação de toda a equipe, de forma a evitar complicações. 
[... Machucou muito a boca, estou com a garganta muito dolorida, dói para engolir, machucou os cantos da boca [...] (P5).

\section{[...] Mexiam comigo e aquilo machucava minha boca [...] (P6).}

Pacientes que recebem suporte ventilatório prolongado estão expostos a uma variedade de complicações decorrentes da intubação endotraqueal, tais como: lesões da mucosa, estenose glótica e subglótica, estenose traqueal e abscesso cricoide, sendo que todas essas complicações estão ligadas diretamente com o tempo de intubação endotraqueal ${ }^{5}$.

Quanto ao acúmulo de secreções no tubo endotraqueal e na cavidade oral, cabe ressaltar que a aspiração, tanto da cavidade oral quanto do tubo endotraqueal, consiste em um cuidado de enfermagem necessário em pacientes na ventilação mecânica, e sua frequência pode ser prescrita pelo enfermeiro, conforme a necessidade do paciente, observando-se, sempre, a permeabilidade das vias aéreas, os alarmes do respirador, além dos níveis de saturação de oxigênio e dos achados clínicos presentes no exame físico.

\section{[... Eu tinha um pouco de secreção, e aquilo me afetava para respirar [...] (P7).}

Devido à idade, fraqueza, ou a patologia, certos pacientes são incapazes de expelir adequadamente suas secreções. As secreções traqueais devem ser aspiradas somente quando necessário, pois a aspiração expõe o paciente a riscos como hipóxia, lesões na mucosa traqueal, atelectasia e infecção ${ }^{1-}$ 5.

Finamente, a afonia, também relatada como dificuldade percebida pelos pacientes em questão, durante o uso da ventilação mecânica, consiste na perda parcial ou total da fala em consequência de lesões nas cordas vocais que podem ser decorrentes do uso da prótese endotraqueal. Por isso, o enfermeiro deverá observar a manutenção adequada da pressão do balonete.

[...] A sensação horrível foi no momento em que tiraram o tubo, o pânico de não poder falar, eu tentei falar, mas, minha nossa, cadê minha voz, eu tinha que falar e não conseguia [...] (P1).

[...] No momento que tiraram o tubo, fiquei sem voz, me preocupei, porque não sabia se aquilo era normal, ou se eu tinha perdido a voz no acidente ou algo do tipo, aquilo me preocupou muito mesmo, mas, depois de uns minutos, já voltou minha voze pude falar, aí foi um alívio, mas mesmo assim, não tinha muita voz, e aquilo demorou uns dias para voltar ao normal [...] (P3).
[...] Senti muita dificuldade para falar depois que tiraram o tubo, a voz demorou a vir e pensei que tinham machucado algo lá dentro [...] (P7).

Pacientes críticos que são tratados com ventilação mecânica podem experimentar o medo, o pânico e a insegurança ao tentar a comunicação e se deparar com a incapacidade de falar. Embora o problema da falta de voz já tenha sido estabelecido na literatura, poucas soluções têm sido oferecidas ou sistematicamente testadas com pacientes de UTI ${ }^{11}$.

\section{Necessidades dos doentes críticos em ventilação mecânica invasiva}

Ao relatarem suas experiências com o uso da ventilação mecânica invasiva, os doentes críticos fizeram referências ainda às necessidades sentidas durante o uso dessa terapêutica.

Neste estudo, as necessidades humanas são, como proposto por Horta (1979), estados conscientes ou inconscientes, resultantes dos desequilíbrios hemodinâmicos, as necessidades não se manifestam, estão latentes e surgem com maior ou menor intensidade dependendo do desequilíbrio instalado ${ }^{12}$.

A enfermagem é a ciência e a arte de assistir o ser humano no atendimento de suas necessidades, tornando-o independente da assistência, quando possível, seja pelo ensino do autocuidado, seja mantendo ou promovendo a saúde em colaboração com outros profissionais ${ }^{12}$.

Assim, compreender as necessidades sentidas por doentes críticos em ventilação mecânica auxilia a equipe de enfermagem a buscar, junto aos pacientes, recursos que tornem essa experiência menos desagradável ${ }^{1-2}$.

A sede, resultado da restrição hídrica ocasionada pela impossibilidade do acesso a recursos líquidos, ou decorrentes da proibição de ingestão de qualquer fonte de água ${ }^{13}$, foi a fonte de desconforto mais citada pelos pacientes.

Ela é decorrente da entubação orotraqueal, que torna impossível para o paciente fechar a boca e engolir, da baixa umidade do ambiente, de restrições hídricas, do uso de oxigênio e de medicamentos, como os opioides, por exemplo, que podem causar diminuição da saliva e secreção como efeitos colaterais $^{13}$

[...] Sentia muita sede, vontade de beber água [...] (P4).

[...] Senti muita sede, queria que molhassem minha boca, fiquei com a boca muito seca [...] (P5).

[...] Senti sede, muita sede, podemos ficar uma semana sem comer, mas sem água não aguentamos dois dias, é impressionante o desespero que dá [...] (P10). 
Um estudo qualitativo de abordagem fenomenológica, que buscou descrever a percepção de 20 enfermeiros de UTIs de um Hospital Universitário da Suécia, quanto à sensação de sede de pacientes ventilados mecanicamente e as intervenções em saciá-la, mostrou que as respondentes manifestaram o desejo em reduzir as fontes de desconfor tos nos pacientes, embora não tenham conseguido perceber que estes sentem sede e, por isso, saciá-la não foi identificado como prioritário ${ }^{13}$.

Ainda foi elencada, como necessidade, pelos respondentes neste estudo, a Comunicação, uma vez que ficava limitada em razão, entre outros, da utilização de via aérea artificial e de drogas sedativas necessárias para aumentar o conforto e permitir a terapêutica.

A impossibilidade de se manter uma adequada comunicação pode produzir estresse tanto para o paciente, que não consegue ser compreendido, como para o profissional, que em diversas vezes não consegue compreender o conteúdo da mensagem emitida pelo paciente, como se pode observar nas falas a seguir:

[...] A comunicação foi a pior, eu queria que alguém fosse até mim e tentava pensar em como fazer aquilo, aína hora não sabia como fazer, mas sempre dava um jeito para chamar a atenção do pessoal [...] (P3).

[...] Tive necessidade de me comunicar, pois você não tem noção como é difícil não poder falar, não conseguir falar, querer se comunicar e não poder, aí eu gesticulava, batia na cama, escrevia para o pessoal me entender. Tentava arranjar uma forma de me comunicar e às vezes era difícil, demorava, e eu ficava mais nervosa ainda [...] (P6).

No estudo cientifico "Communicating With Mechanically Ventilated Patients: State of the Science", a comunicação enfermeiro-paciente foi considerada essencial para 0 desenvolvimento de uma terapêutica com sucesso em pacientes que fizeram uso da ventilação mecânica ${ }^{11}$. Quando os pacientes não podem responder verbalmente, a comunicação limita-se a gestos e sinais com a cabeça, que são os principais meios de comunicação utilizados pelos doentes críticos. 0 gesto é a forma de comunicação mais comum, usado como meio de comunicação em pacientes em uso de ventilação mecânica, serve para validar e construir um repertório mutuamente compreendido entre paciente e enfermeiro ${ }^{11}$.

Anecessidade de comunicar-seé inerente ao ser humano e contempla a sua possibilidade de socialização e adaptação a um ambiente que difere em muito daquele em que rotineiramente habita e com o qual estabelece suas relações.

Entretanto, não só a alteração da rotina relacionada à necessidade de comunicação foi relatada pelos pacientes, mas também as alterações de rotina em geral foram percebidas como fator de estresse.

\begin{abstract}
[...] A questão mais complicada para mim foi alterar minha rotina, a gente está acostumado a viver de uma forma, e quando tu acordas do coma, tu tá vendo uma coisa que não é tua rotina, e pensa, porque eu não podia fazer o que eu fazia antes, $e$ aí tu tens que se adaptar a tantas coisas novas, primeiro vendo pessoas novas, depois tentando se comunicar e não poder, e aí tu vê aquele monte de gente que tu não conhece [...] (P3).
\end{abstract}

De acordo com o estudo realizado na UTI médicocirúrgico do Hospital Gelre (Holanda), proporcionar e fornecer informações e esclarecimentos aos gravemente doentes, durante a ventilação mecânica, foi percebido, pelos pacientes, como tranquilizador. Os dados apontaram que essas atitudes, por parte dos profissionais, resultaram em diminuição do medo e da insegurança, ou seja, explicar previamente os procedimentos a serem realizados diminuiu o desconforto, deixando os pacientes mais conscientes do que estava por acontecer, de forma que puderam ficar mais relaxados e aptos a lidar com o estresse dos procedimentos, diminuindo a insegurança e a angústia de não saberem 0 que esta acontecendo ${ }^{14}$.

Nenhum ser humano está preparado para alterar suas rotinas diárias, principalmente quando estas vêm acompanhadas de um processo patológico, que poderão ser, em muitos casos, definitivos ${ }^{15}$.

\section{CONSIDERAÇÕES FINAIS}

Os resultados deste estudo evidenciaram as dificuldades e necessidades que os pacientes críticos encontram durante o uso da ventilação mecânica. As dificuldades relatadas relacionaram-se especialmente à presença da via aérea artificial, sendo elas: sensação de sufocamento, náuseas, lesões decorrentes do tubo endotraqueal, acúmulo de secreções no tubo endotraqueal e cavidade oral e afonia. Ainda, os pacientes referiram necessidades de comunicação, sede e alterações da rotina pessoal.

As experiências dos pacientes críticos com a ventilação mecânica podem contribuir para uma melhor avaliação de suas necessidades, muitas delas não encontradas na literatura atual, vindo ao encontro de um cuidado de enfermagem mais efetivo e humanizado a essa clientela.

A enfermagem está inserida em um meio que busca o aprimoramento de suas ações em um processo contínuo, principalmente em áreas de grande poder tecnológico que confrontam o profissional com equipamentos cada vez mais sofisticados, o que requer um contínuo interesse de pesquisas nessa área. Salientase, assim, a importância de estudos nesta área, que necessitam ter, como objetivo principal, a excelência na assistência de futuros pacientes críticos que venham a utilizar o recurso da ventilação mecânica. 


\section{REFERÊNCIAS}

1. Cintra EA, Nishide VM, Nunes WA. Assistência de enfermagem ao paciente gravemente enfermo. $2^{\mathrm{a}}$ ed. São Paulo: Atheneu; 2008.

2. Knobel E. Condutas no paciente grave. $3^{\mathrm{a}}$ ed. São Paulo: Atheneu; 2006.

3. Schwonke CRGB, et al. Perspectivas filosóficas do uso da tecnologia no cuidado de enfermagem em terapia intensiva. Rev Bras Enferm. 2011; 64(1): 189-92.

4. Silva RCL, Porto IS, Figueiredo NMA. Reflexões acerca da assistência de enfermagem e o discurso de humanização em terapia intensiva. Esc Anna Nery. 2008; 12(1): 156-59.

5. Azevedo EG. Enfermagem em unidade de terapia intensiva. $2^{\mathrm{a}}$ ed. Goiânia: Ed AB; 2009.

6. Passos E, et al. Papel da enfermagem na assistência ao paciente com ventilação mecânica In: $2^{\circ}$ Consenso Brasileiro de Ventilação Mecânica. J Bras Pneumol. 2000; 26(2): 27-34.

7. Victora CG, Knauth DR, Hassen MNA. Pesquisa qualitativa em saúde: uma introdução ao tema. Porto Alegre: Tomo Ed; 2000.

8. Moraes R. Mergulhos discursivos: análise textual qualitativa entendida como processo integrado de aprender, comunicar e interferir em discursos. In: Galiazzi MC, Vicente J, organizadores. Metodologias emergentes de pesquisa em educação ambiental. ljuí: Unijuí; 2005.

9. Tallo FS. Alterações da mecânica respiratória normal e influência das vias aéreas artificiais na ventilação mecânica. In: Mendes NT, Tallo FS, Guimarães HP. Guia de ventilação mecânica. São Paulo: Atingiu; 2011.

10. Farias AMC, Silvoso AM, Neves JLB. Entonação e traqueostomia. In: Carvalho CRR. Ventilação mecânica. São Paulo: Atheneu; 2006.

11. Happ MB. Communicating with mechanically ventilated patients: state of the science. AACN Clinical Issues; 2001; 12(2): 247-58.

12 Horta WA. O processo de enfermagem. São Paulo: EPU/EDUSP; 1979.

13 Landstrom M, Rehn IM, Frisman GH. Perceptions of registered and enrolled nurses on thirst in mechanically ventilated adult patients in intensive care units: a phenomenographic study. Intensive Crit Care Nurs. Elsevier, 2009; 25: 133-39.

14 Hofhuis JGM, et al. Experiences of critically ill patients in the ICU. Intensive Crit Care Nurs. Elsevier, 2008; 24: 300-13.

15 Silveira TM, Caldas CP, Carneiro TF. Cuidando de idosos altamente dependentes na comunidade: um estudo sobre cuidadores familiares principais. Cad Saude Publica. 2006; 22(8): 1629-638. 